\title{
Analysis of Catfish Supplier Services Quality in Catfish Food Stall in The City of Yogyakarta
}

\author{
Rifqi Satriasakti, Kuncoro Harto Widodo, and Didik Purwadi* \\ Department of Agroindustrial Technology, Universitas Gadjah Mada, Yogyakarta
}

\begin{abstract}
This study aimed to determine the characteristics of catfish food stalls, to analyze the gap between consumer perceptions and expectations, to analyze the level of satisfaction of catfish food stalls for logistics services, and to understand the service attributes of catfish suppliers considered important by consumers. Components of service quality were analyzed based on nine dimensions of logistics service quality. The methods used for analyzing service quality in this study was GAP, CSI, and IPA. The order amount was mostly above $6 \mathrm{~kg}$, amounting $43 \%$ of the total catfish orders. The overall gap value of the variables was 0.293 . The CSI value was $84.49 \%$ which means that consumers were very satisfied with the supplier's performance. There were 5 attributes in the quadrant with a very high level of importance, but the performance was still low.
\end{abstract}

\section{Introduction}

The sale of catfish on traditional markets is largely needed by two types of consumers, the needs of household consumers and the needs of food stalls. The growth of food stalls is very rapid with a very high market capacity for catfish. Catfish food stalls are the place to absorb the most consumed catfish supply [1]. Generally, the continuity of catfish supply needs in food stalls is consumers' when compared to the needs of catfish supply in supermarkets, which ensures continuous demand from the food stalls market.

The high need for catfish by food stalls indicates the important role of catfish suppliers in fulfilling the logistical needs of food stalls in the city of Yogyakarta. Due to the very tight competition between suppliers, it is considered a duty for every supplier to maintain the loyalty of each customer. The similarity in goods requires suppliers to maintain service performance so that consumers do not feel disappointed and to find another supplier, replacing their role as partners in meeting the consumer's logistics needs. Measurement of the supplier's performance is very important in order to evaluate the extent of the supplier's role in the fulfillment of catfish supply needs for the food stalls in the city of Yogyakarta. At the time, suppliers have never measured their performance nor knowing how well the other performance of other suppliers in fulfilling their customer's needs. This study will broadly measure the performance of the suppliers for the catfish food stalls in the city of Yogyakarta. The output should be able to become a reference for how the suppliers must maintain and improve their performance.

\footnotetext{
*Corresponding author: didik@ugm.ac.id
} 
The importance of the role of catfish supplier services in meeting the consumers' needs is the key to the sustainability of catfish stall business. In this research, we analyzed the service quality of catfish suppliers based on logistic service quality variables. The first variable is the information quality, which focuses on seeing customer's perceptions of the information provided by suppliers regarding the supplied catfish. The second variable is the order procedures which are variables that discuss the effectiveness, efficiency, and consistency of supplier performance in the procedure for ordering catfish. The third variable is the order release quantity which is a variable of availability of catfish provided by suppliers to consumers. The fourth variable is the timeliness which is a variable that evaluates whether the orders sent by catfish suppliers are on time and is in accordance with the agreement. The fifth variable is the order accuracy which is a variable related to the suitability of the goods ordered including the number, type, and size of catfish. The sixth variable is the order condition variable that relates to the condition of the ordered product ordered both from damage and freshness of the product. The seventh variable is the order discrepancy which is a variable relating to the handling of a supplier regarding the incompatibility of orders after the order is made by the consumer to the supplier. The eight variable is the personal contact quality which focuses on the discussion of customer orientation towards personal contact given in solving problems that are in the field, and the ninth variable is the order quality which is a variable regarding the overall quality that has been ordered.

\section{Materials and Methods}

\subsection{Research Approach}

This research was conducted in November 2018 until April 2019 in the city of Yogyakarta where there are 14 sub-districts in it.

The indicators and construction of this study can be seen below [2-5]:
a. Information Quality (two attributes: clear information, honest information)
b. The ordering procedure (three attributes: easy, speed, responsible procedure)
c. Order release quantity (four attributes: stock availability, stockout, maximum order, minimum order)
d. Timeliness (three attributes: speed, delay, loading)
e. Order accuracy (three attributes: quantity, types, size)
f. Order Condition (three attributes: physical condition, freshness, defect)
g. Order discrepancy (four attributes: delay information, fast response, right response, different quality response)
h. Order personal contact quality (three attributes: understanding, problem solving, product knowledge)
i. Order quality (two attributes: needs, suitable product)

\subsection{Research Method}

The method was a survey and the data were collected using a questionnaire approach. The research variables consisted of the service quality of the supplier with 9 variables containing 27 attributes. 


\subsubsection{Validity}

The main idea of validity is the extent of the accuracy of a measuring instrument in carrying out its size function. The hypothesis test used in this study was as follows:

H0: Correlation of item scores with total score is not significant (invalid)

H1: Correlation of item score with total score is significant (valid)

The criteria for acceptance/rejection of the hypotheses were as follows: Rejection of $\mathrm{HO}$ if the probability calculated $\leq$ the probability set at 0.05 (sig2-tailed $\leq \alpha 0.05$ ) [6] or it can also be seen from $r$ table and $r$ count. If the value of $r$ count $>r$ table, then the item about the questionnaire is declared valid. If the value of $r$ counts $<r$ table, then the item about the questionnaire is declared invalid [7].

\subsubsection{Reliability}

The reliability testing was done using Cronbach Alpha value criteria. If the value of the reliability coefficient (Cronbach's Alpha) > 0.6 then, the instrument has good reliability or in other words, the instrument is reliable or trustworthy [7].

\subsubsection{Sample Method}

The number of respondents in this study was 100 respondents from all sub-districts in the city of Yogyakarta. The sampling method used was non-probability sampling with purposive sampling, for unknown populations and the proportion of the population was considered $50 \%$. The total number of respondents was 100 respondents [8].

\subsection{Data Analysis}

Data analysis used GAP analysis method, CSI (customer satisfaction index), and IPA (importance performance analysis). The value obtained between the expectation gap and perception is also called Servqual score. Servqual Score $=$ Perception Score $(\mathrm{P})$ - Expectation Score (I) [9]. The Customer Satisfaction Index (CSI) is a method that uses an index to measure the level of satisfaction of consumers based on certain attributes. The formula for the Customer Satisfaction Index (CSI) as follows [10],

$$
\mathrm{CSI}=\frac{T}{5 Y} X 100 \%
$$

\footnotetext{
$T:$ Total amount (IxP)

$Y$ : Total I

I : Importance

$\mathrm{P}$ : Performance
}

The IPA method was analyzed using SPSS by looking at the average score of the level of performance and the average score of importance. The $\mathrm{X}$ axis is the level of performance and the $\mathrm{Y}$ axis is the level of importance. Below is the Importance performance analysis (IPA) formula [11] :

$$
X=\frac{\Sigma X i}{n} \quad Y=\frac{\Sigma Y i}{n}
$$

$X$ : Average score for the level of performance

$Y:$ Score of the average level of interest

$n:$ Number of respondents 


\section{Results and Discussion}

\subsection{Customer Characteristic}

Respondents who have filled out the questionnaire at the time of the research on average used a single supplier with a percentage of $98 \%$. Orders made by respondents to $100 \%$ suppliers in 1-2 days. From 100 respondents, $82 \%$ of them used motorbikes for the catfish logistics distribution, and the rest used cars/lorry, $63 \%$ of them made prepayments and $37 \%$ made payments at the end after the distribution process is done. The other characteristics of the respondents are further discussed in the following sections.

\subsubsection{Location Respondents}

In knowing the location where the catfish food stalls on respondents is described in table 1 :

Table 1. Table location of respondents

\begin{tabular}{clc}
\hline No & Sub-District & Number of Samples \\
\hline 1 & Gondokusuman & 4 \\
2 & Umbulharjo & 22 \\
3 & Danurejan & 4 \\
4 & Gedongtengen & 3 \\
5 & Gondomanan & 2 \\
6 & Jetis & 6 \\
7 & Kotegede & 3 \\
8 & Kraton & 4 \\
9 & Mantrijeron & 11 \\
10 & Mergangsan & 7 \\
11 & Ngampilan & 3 \\
12 & Pakualaman & 3 \\
13 & Tegalrejo & 18 \\
14 & Wirobrajan & 10 \\
\hline
\end{tabular}

Based on the information in table 1, the location of the respondents covered all subdistricts in Yogyakarta. The majority of respondents were in the Umbulharjo sub-district with 22 respondents. Based on the observations, the Umbulharjo sub-district has the highest number of catfish food stalls. This sub-district also has more villages compared to the other sub-districts in the city of Yogyakarta.

\subsubsection{Position of Respondent}

The position of respondents who participated and filled out the questionnaire is described in table 2:

Table 2. Position of respondents

\begin{tabular}{clc}
\hline No & Position & Number \\
\hline 1 & Owner & 84 \\
2 & Employee & 16 \\
\hline
\end{tabular}


Based on the table above, it can be seen that $84 \%$ of those filling out the questionnaire were catfish food stall owners and $16 \%$ were employees worked for the stall. The data also showed that the majority of the sales of catfish food stalls were more directly controlled by the owner than handing it over to the employees, but both of them know well how suppliers work. Employees who filled out this questionnaire were also confirmed to be employees who were given great responsibility by the owner and had worked long at the food stall and it was ensured that the employees who filled out the questionnaire knew very well why the catfish food stalls wanted to use catfish suppliers instead of buying directly into the market.

\subsubsection{Duration of Use of Supplier}

Based on the results, most respondents have used suppliers for over 6 years. This indicated that the respondents of the catfish food stalls have partnered with their suppliers for a long time. The duration of usage of the supplier is presented in Fig. 1.

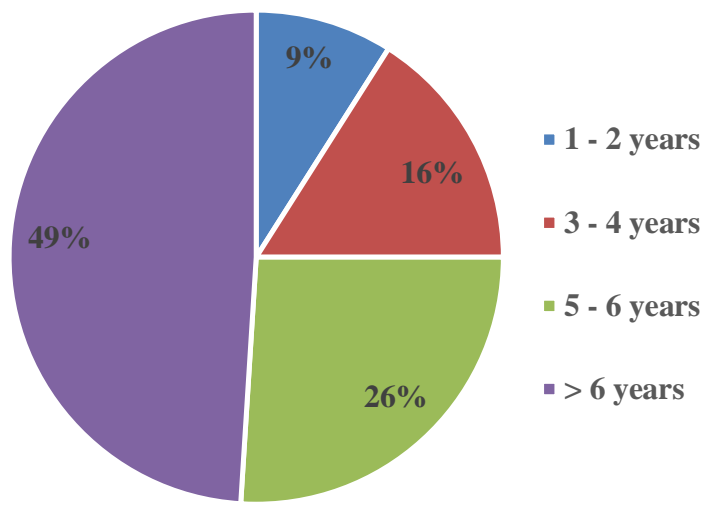

Fig. 1. Duration characteristics of Supplier Use

\subsubsection{Order Quantity}

The characteristics of respondents who ordered catfish with certain quantity were categorized by $1-2 \mathrm{~kg}, 3-4 \mathrm{~kg}, 5-6 \mathrm{~kg}$, and $>6 \mathrm{~kg}$. The results showed that the respondents who ordered in the amount of $>6 \mathrm{~kg}$ were $43 \%$ from the total respondent, $5-6 \mathrm{~kg}$ amounted $29 \%, 3-4 \mathrm{~kg}$ amounted $23 \%$, and $1-2 \mathrm{~kg}$ amounted $5 \%$ of the total. The results are described in Fig. 2.

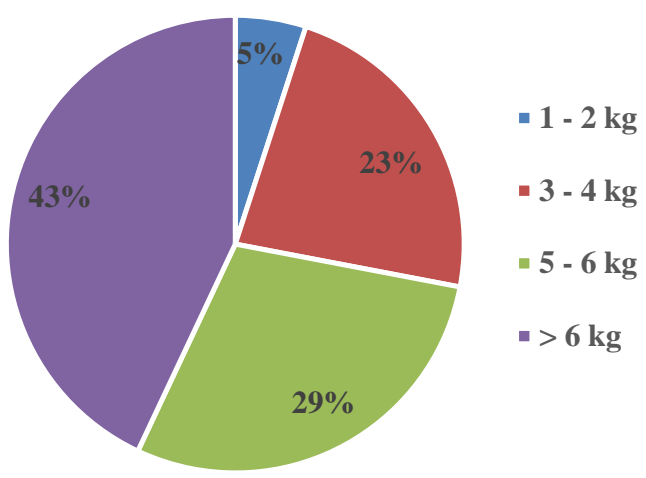

Fig. 2. Proportion of order quantity by costumer 


\subsection{Validity}

Based on the results of the questionnaire validity test, it can be concluded that all statements are valid because the acquisition of $r$ count $>r$ table or can be seen also from sig2-tailed $\leq \alpha$ 0.05 . All items in the question on the expectation variable are declared valid because $r$ count is greater than $r$ table $(0.334)$. The second is the validity of the perception questionnaire. All items in the question on the perception variable are declared valid because $r$ count is greater than $r$ table (0.334).

\subsection{Reliability}

The following are the results of the reliability of the perception and expectation questionnaire:

Table 3. Reliability of the perception and expectation questionnaire

\begin{tabular}{lccl}
\hline Variable & Cronbach's Alpha & $\begin{array}{c}\text { Cronbach Alpha } \\
\text { Provisions }\end{array}$ & Result \\
\hline Perception & 0.725 & 0.6 & Reliable \\
Expectation & 0.729 & 0.6 & Reliable \\
\hline
\end{tabular}

All question items that measure research variables are stated to be reliable because the Cronbach's alpha value is greater than 0.6.

\subsection{Gap Analysis}

Table 4. Results of gap analysis

\begin{tabular}{lccc}
\hline Dimension & $\begin{array}{c}\text { Average } \\
\text { perceptions }\end{array}$ & $\begin{array}{c}\text { Average } \\
\text { Expectations }\end{array}$ & Gap (P-I) \\
\hline Information quality & 4.26 & 3.73 & 0.535 \\
Ordering procedures & 4.20 & 3.99 & 0.217 \\
$\begin{array}{l}\text { Ordering release } \\
\text { quantity }\end{array}$ & 4.32 & 4.17 & 0.148 \\
Timeliness & 4.28 & 4.07 & 0.207 \\
Order accuracy & 4.32 & 4.01 & 0.313 \\
Order Condition & 4.23 & 3.82 & 0.417 \\
Order Discrepancy & 4.11 & 4.25 & -0.138 \\
Order personal & 4.06 & 3.4 & 0.657 \\
contact quality & 4.30 & 4.02 & 0.28 \\
Order quality & $\mathbf{4 . 2 3}$ & $\mathbf{3 . 9 4}$ & $\mathbf{0 . 2 9 3}$ \\
\hline Total Average & & & \\
\hline
\end{tabular}

Based on the results of the gap analysis, the average value of the overall gap in the nine dimensions is 0.293 . The lowest gap calculation results on the dimensions of the order discrepancy with a value of -0.138 . then the order release dimension is 0.148 , then timeliness 0.207 , ordering procedures 0.217 , order quality 0.28 , order accuracy 0.313 , order condition 0.417 , information quality 0.535 , and personal contact quality order 0.657 whereas, the average yield level is 0.293 . So improvements still need to be made because there are still negative values on one variable and 5 attributes in the existing variables. These attributes 
include attributes that provide timely delivery of orders according to agreement $(-0.61)$, attributes do not provide difficulties in ordering with a minimum amount $(-0.25)$, attribute responsibility for receiving extra orders $(-0.37)$, attributes notifying consumers if they occur delay (-0.69), and the attribute gives the right response if a catfish delivery problem occurs $(-0.41)$.

\subsection{Customer Satisfaction Index}

The CSI analysis discussed the level of satisfaction of consumers by considering the level of interest of consumers and the level of performance of suppliers based on the point of view of consumers who have obtained the value from the stage of data collection. This analysis was taken from data based on variables that were considered influential and affected consumer satisfaction. The following is the result of calculating the Customer Satisfaction Index:

$$
\mathrm{CSI}=\frac{T}{5 Y} \times 100 \%=\frac{\mathbf{1 0 7 . 1}}{\mathbf{5 3 5 . 0 5}} \times 100 \%=84.49 \%
$$

After calculation, the CSI value is $84.49 \%$. If the CSI value is $80 \%$ or above, it shows that consumer satisfaction is in the high category [10].

\subsection{Importance Performance Analysis}

The results of importance performance analysis can be seen in the figure 3:

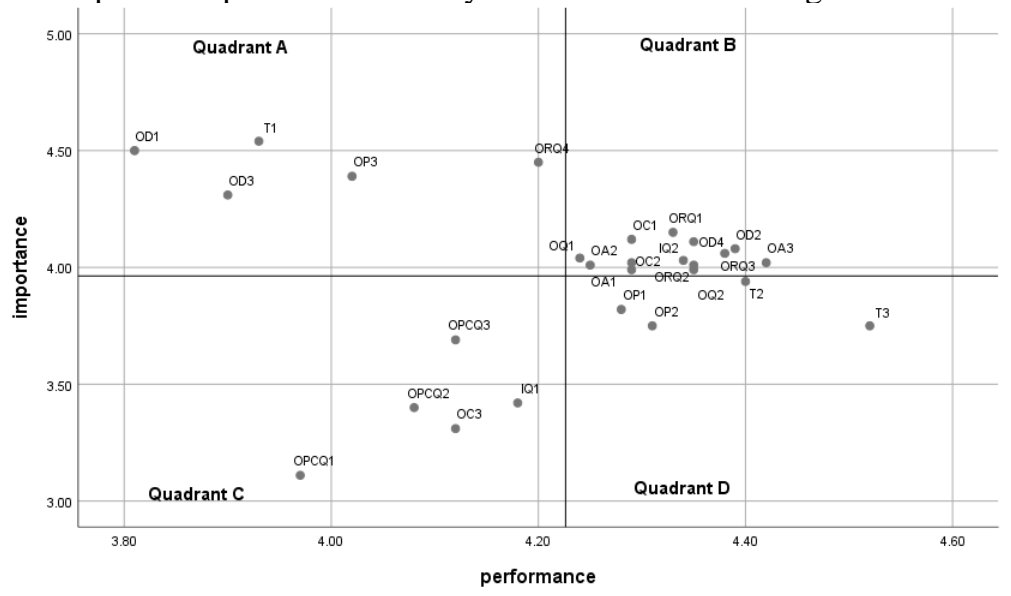

Fig. 3. Importance-Performance Index

The results obtained from importance performance analysis are five (5) attributes that are in quadrant A, thirteen (13) attributes are in the quadrant B, five (5) attributes are in quadrant C, and four (4) attributes are in quadrant D. Quadrant A is the first priority where catfish food stalls as consumers feel this attribute is a very important attribute and have high expectations of service on this attribute, but in reality the performance provided by suppliers as service providers has not been maximized. These attributes are as follows:

a. Responsibility for the process of receiving more catfish orders (extra) (item 5)

b. Does not provide difficulties in ordering with the minimum number of orders (item9)

c. Provide timely delivery of orders in accordance with the agreement of suppliers and consumers I (item 10)

d. Notify consumers if there is a delay in shipping orders (item 19)

e. Give the right response if there is a problem in sending catfish orders (item 21) 
This result can be related to the P-I gap value. The five attributes still get a negative (-) difference between perceptions and expectations

Quadrant B is a quadrant containing attributes that are also considered important by consumers and the performance provided by suppliers is considered good by consumers. Therefore, suppliers that supply catfish to catfish food stalls in the city of Yogyakarta must maintain performance on this attribute so that they can continue to be better and customer loyalty is maintained on this attribute. In addition, this attribute can also be made an advantage that can be positively worth of mouth. The attributes in this quadrant are as follows:
a. Providing honest information about catfish supplied (item2)
b. Having catfish stock availability as requested (item 6)
c. Notifies if the stock cannot fulfill the order (item 7)
d. Does not provide difficulties in ordering with the maximum number of orders (item 8)

e. Providing conformity to the quantity (quantity) of catfish with orders that come to consumers (item 13)

f. Provide the suitability of the type of catfish sent to consumer demand (item 14)

g. Providing conformity to catfish size sent with consumer demand (item 15)

h. Send catfish in good condition (item 16)

i. Send catfish in fresh condition (item 17)

j. Give a quick response if there is a problem with catfish delivery (item 20)

k. Give a satisfactory response to the report if there is a difference in quality (item 22)

1. Meet the technical needs of consumers of products ordered (26)

m. Provides conformity to product conditions with orders (27)

Quadrant C contains two (2) attributes from the order discrepancy dimension, one (1) attribute from the timeliness dimension, one (1) attribute from order release quantity and one (1) attribute from ordering procedures.

Quadrant D is a quadrant that contains service attributes that according to consumers the performance is good and even tends to exceed what is expected by consumers. The level of importance of this attribute by consumers is low. Therefore, suppliers do not have to focus on attributes that are in this quadrant. The following are the attributes that are in the D quadrant :

a. Providing easy procedures for ordering catfish (item 3)

b. Gives speed in the catfish ordering procedure (item 4)

c. Meet the delivery if there is a pending order (not on time) (item 11)

d. Gives speed in the process of handling materials (loading / unloading goods) (item 12)

\section{Conclusion}

Based on the results, It can be concluded that in a period of time, most catfish food stalls in Yogyakarta area ordered catfish supply from the suppliers with a quantity of more than $6 \mathrm{~kg}$. The performance of the entire suppliers has satisfied consumers where it can be seen from CSI results $(84.49 \%$,) but priority must still be made because there are still negative gap values on 5 attributes. The five attributes are all included in the priority scale of improvement in the IPA method because they have high importance and low performance. Other attributes that are considered important are attributes included in the quadrant with high importance and good performance. The five attributes that must be prioritized for improvement are the attributes of responsibility for the process of receiving more catfish (extra) orders (item 5), not giving difficulties in order with the minimum order quantity (item 9), providing timely delivery of orders in accordance with the agreement suppliers and consumers (item 10), 
notifying consumers if there is a delay in the delivery of orders (item 19), and providing an appropriate response if a problem occurs in the delivery of catfish orders (item 21).

\section{References}

1. Darseno, Buku Pintar Budi Daya dan Bisnis Lele, 8 (2010)

2. J. T. Mentzer, D. J. Flint, J. L. Kent, Dev. A. Log. Qual. Sca 20, 1 (1999)

3. S. Zaelain, M. Iranmanesh, S. jafarzadeh, Hal. Log. Serv. Qual. :Con. Mod. Emp. Evi 120, $11(2018)$

4. B. Versa, H. Subagio, Peng. Log. Serv. Qual. Ter. Cust. Sat. Cat. Emc. Pt. Sat. Adi. 2. 2 (2014)

5. Y. Politis, A. Giovanis, S. Binioris, Log. Serv. Qual. Its. Eff. Cus. Sat. Man. Com. Sup. Cha 9, 2 (2013)

6. J. Auzar, Irfan, M. Saprinal, Metodologi Penelitian Bisnis, 204 (2014)

7. S. Rajarho, Uji Validitas dengan Rumus Pearson SPSS, https://www.konsistensi.com/2013/03/uji-validitas-data-dengan-rumus-pearson.html

8. S. Lameshow, D. W. Hosmer Jr, J. Klar, S. K. Lwanga, Ade. Sam. Siz. Hea. Stu. 1 (1990)

9. F. Tjiptono, Service Management Mewujudkan Layanan Prima. 148 (2011)

10. B. Keki. R, Beyond Customer Satisfaction to Customer Loyalty The Key yo Greater Profitability.123 (1996)

11. J. A. Martilla, J. C. James, Imp-Per. Anal. 41, 1 (1977) 